\title{
RECENT EVOLUTIONS OF THE ROMANIAN CAPITAL MARKET IN THE CONTEXT OF FINANCIAL CRISIS
}

\author{
PhD Professor PhD Bogdan Dima, West University of Timişoara, bogdandima2001@gmail.com \\ PhD LecturerPhD Aurora Murgea, West University of Timişoara, auroramurgea@gmail.com \\ PhD Professor Gabriel Marilen Pirtea, West University of Timişoara, marilen.pirtea@gmail.com
}

ABSTRACT: The favorable institutional and functional evolution of the Romanian capital market was break out by the negative consequences of the financial crisis. Thus, the objective of this paper is to analyze the current evolutions and to identify some of the crisis' pathology characteristics. Some conclusions are drawn and some further research directions are indicated.

Keywords: Romanian capital market, financial crisis, Quandt-Andrews test, BET, BET-C, BET-FI

JEL Codes: G10,G15

\section{Introduction}

A lot of other researchers have supported the idea that the financial markets are intrinsically unstable (see Skott,P[1995], Kregel,J.A.[1998], Schroeder,S[2003]). In the stable growth phases riskier investment practices and shakier financial structures will develop. Partly for this reason we are passing the sixth major readjustment of the financial system over the past 21 years. In 1987, we saw the equity market crash and rebound; in the early 1990's, the junk bond market collapsed and shrunk; at the same time, the real estate market unraveled and then eventually re-spooled; in 1998, the Asian currency crisis descended and then lifted; and, of course, the Internet economy fell back to earth in the first years of this decade before a parachute eventually opened. Also a crises started in a part of a world due to the globalization of the financial markets rapidly contagions the other markets (see Frankel and Schmukler [1998].As noticed by Obstfeld and Taylor in 2004 "at the turn of the twenty first century the merits of international integration are under more forceful attach than at the anything since the 1940's. The risks of global financial integration outweigh the benefits".

In December 2007 a study by Păun, Braşoveanu and Muşatescu [2007, 86] concludes that: „The indicator ARA calculated for the Romanian capital market indicates a decreasing risk aversion. This evolution could be explained by a higher efficiency of this market (especially at institutional and regulatory level), a higher experience of the Romanian investors and increasing investment opportunities, an increase in the income level that generated a higher interest for risky assets and a different attitude towards risks". But this evaluation should be reformulated in the context of the global financial crisis and of the market reaction to the increase in the uncertainty about future evolutions. Thus, the objective of this paper is to analyze the current evolutions and to identify some of the crisis' pathology characteristics. Some conclusions are drawn and some further research directions are indicated.

\section{The Romanian capital market in the shadow of the crisis}

The contradictory news from the American economy has lead to high volatilities in all capital markets including Romanian's one. If one looks at the main causes of the volatility in the last decade (a strong emotional status which overwhelms the main stream of the investors due to the existence of some positive factors - sentiments of euphoria, joy, greed - or some negative factors sentiments of apathy, risk aversion, fear or even panic; the globalization of the capital markets) and 
analyses the last crises evolution is easy to notice the presence of both main factor of volatility and of course of their results.

The global overview of the Romanian capital market indexes reflects:

- An "auto-sustainable" downward trend for the market prices starting with August 2007;

- A tendency for increase in the market intrinsic volatility as an expression of the unbalanced bid/ask ratio due to the increase of uncertainty in the transactional environment.

More detailed information could be provided by the general statistic properties of the indexes as they are captured by their histograms (Graphic 2).

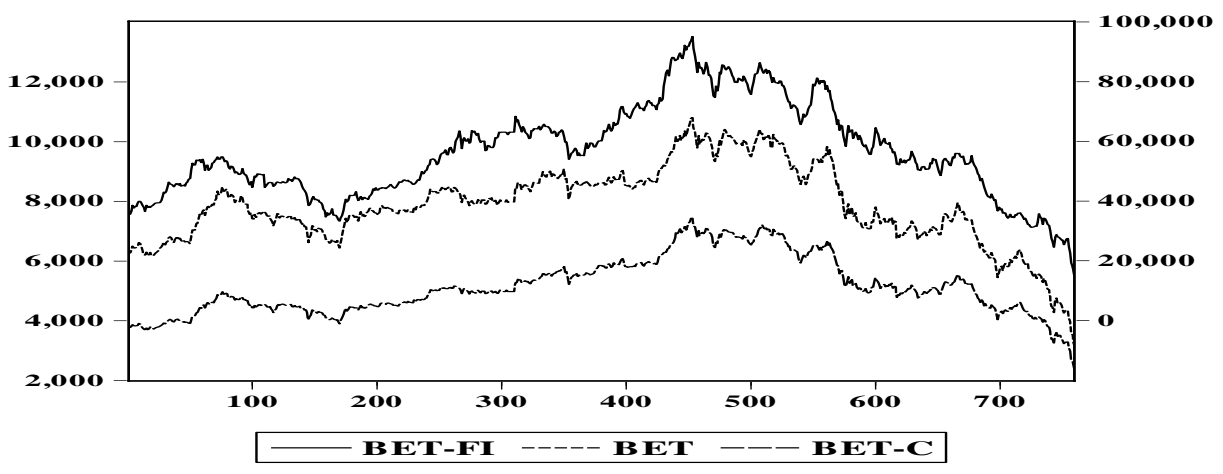

Fig. No. 1 -Recent evolutions of the Romanian capital market indexes
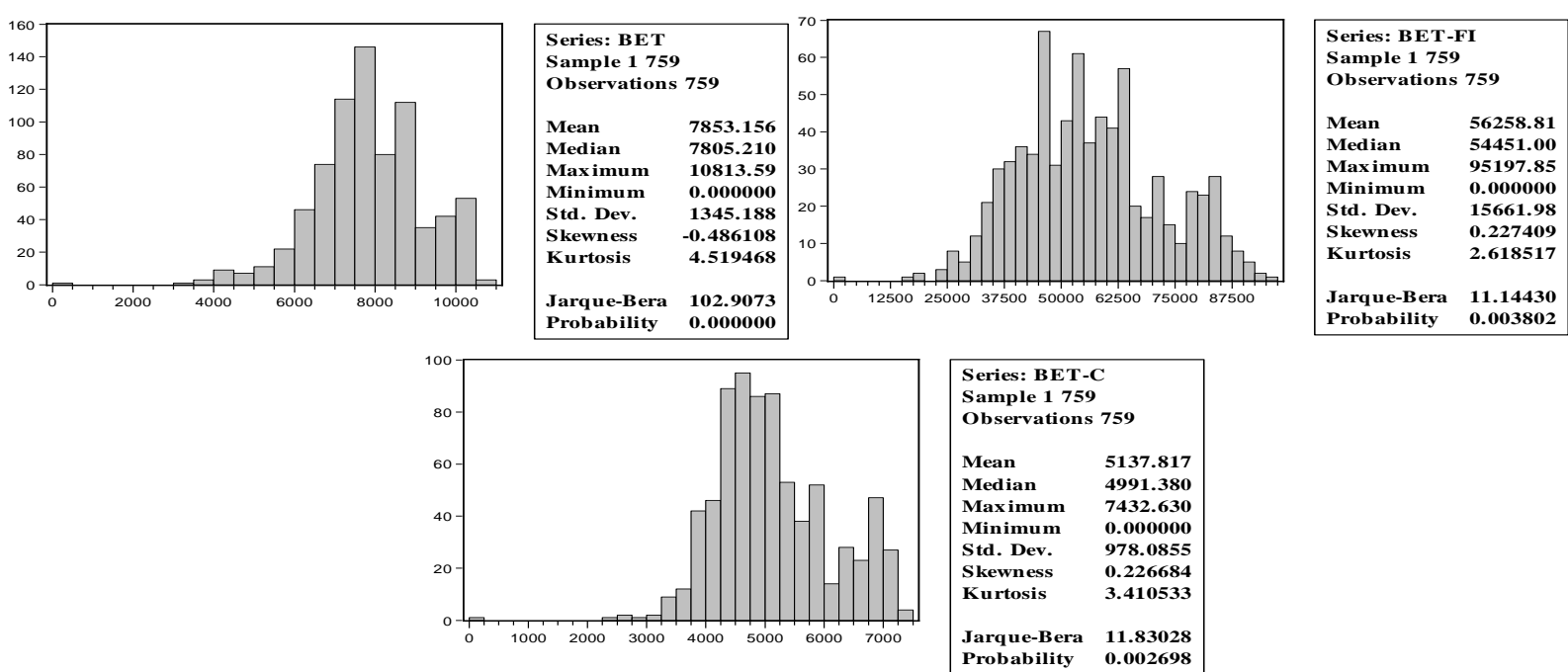

Fig. No. 2 -General statistics for market indexes

The analysis of these properties enlightens:

- A non-normal distribution as a consequence of a non-informational efficient (at least in a "strong" sense) market evolution;

- An important level of volatility (measured for instance by the variance coefficient- the ratio between the standard deviation and the mean) (higher for BET-FI) and lower for BET-C;

- A relative reduced capacity to absorb the exogenous shocks (as these are captured by the "spikes" in distribution).

Since the issue of a "close to normal" distribution is a pre-critical condition for the "market efficiency" analysis there are required more analytical empirical distribution tests: 
Empirical Distribution Test for BET

\section{Empirical distribution tests for indexes}

Hypothesis: Normal

Sample: 1759

Included observations: 759

\begin{tabular}{|c|c|c|c|}
\hline Method & Value & Adj. Value & Probability \\
\hline Lilliefors (D) & 0.046908 & NA & 0.0004 \\
\hline Cramer-von Mises (W2) & 0.347612 & 0.347841 & 0.0001 \\
\hline Watson (U2) & 0.330806 & 0.331023 & 0.0001 \\
\hline Anderson-Darling (A2) & 2.634030 & 2.636643 & 0.0000 \\
\hline
\end{tabular}

Method: Maximum Likelihood - degree of freedom corrected (Exact Solution)

\begin{tabular}{|c|c|c|c|c|}
\hline Parameter & Value & Std. Error & z-Statistic & Prob. \\
\hline MU & 7853.156 & 48.82721 & 160.8356 & 0.0000 \\
\hline SIGMA & 1345.188 & 34.54882 & 38.93584 & 0.0000 \\
\hline Log likelihood & -6544.529 & \multicolumn{2}{|c|}{ Mean dependent var. } & 7853.156 \\
\hline No. of Coefficients & 2 & \multicolumn{2}{|c|}{ S.D. dependent var. } & 1345.188 \\
\hline
\end{tabular}

Empirical Distribution Test for BET-C

Hypothesis: Normal

Sample: 1759

Included observations: 759

\begin{tabular}{|c|c|c|c|}
\hline Method & Value & Adj. Value & Probability \\
\hline Lilliefors (D) & 0.087680 & NA & 0.0000 \\
\hline Cramer-von Mises (W2) & 1.517064 & 1.518063 & 0.0000 \\
\hline Watson (U2) & 1.359193 & 1.360089 & 0.0000 \\
\hline Anderson-Darling (A2) & 9.403168 & 9.412496 & 0.0000 \\
\hline
\end{tabular}

Method: Maximum Likelihood - degree of freedom corrected (Exact Solution)

\begin{tabular}{lrrrr}
\hline \multicolumn{1}{c}{ Parameter } & Value & Std. Error & z-Statistic & Prob. \\
\hline \hline \multicolumn{1}{c}{ MU } & 5137.817 & 35.50225 & 144.7181 & 0.0000 \\
\multicolumn{1}{c}{ SIGMA } & 978.0855 & 25.12044 & 38.93584 & 0.0000 \\
\hline \hline Log likelihood & -6302.643 & Mean dependent var. & 5137.817 \\
No. of Coefficients & 2 & S.D. dependent var. & 978.0855 \\
\hline \hline
\end{tabular}

Empirical Distribution Test for BET-FI

Hypothesis: Normal

Sample: 1759

Included observations: 759

\begin{tabular}{llll}
\hline \hline Method & Value & Adj. Value & Probability \\
\hline \hline
\end{tabular}

$\begin{array}{llll}\text { Lilliefors (D) } & 0.053780 & \text { NA } & 0.0000\end{array}$




$\begin{array}{llll}\text { Cramer-von Mises (W2) } & 0.546312 & 0.546671 & 0.0000 \\ \text { Watson (U2) } & 0.478665 & 0.478981 & 0.0000 \\ \text { Anderson-Darling (A2) } & 3.893072 & 3.896935 & 0.0000\end{array}$

Method: Maximum Likelihood - degree of freedom corrected (Exact Solution)

\begin{tabular}{lrrrr}
\hline \multicolumn{1}{c}{ Parameter } & Value & Std. Error & z-Statistic & Prob. \\
\hline \hline \multicolumn{1}{c}{ SIGMA } & 56258.81 & 568.4938 & 98.96117 & 0.0000 \\
\multicolumn{1}{c}{15661.98} & 402.2509 & 38.93584 & 0.0000 \\
\hline \hline Log likelihood & & & 56258.81 \\
No. of Coefficients & -8407.649 & Mean dependent var. & 15661.98 \\
\hline \hline
\end{tabular}

It could be noticed the fact that these tests rejects for all the indexes the null of a "normal" distribution. Or, since a larger "gap" between the empirical distribution and the "normal" one could be seen as a measure of the market' informational dysfunctions, it could be conclude that for the considered time span the Romanian capital market does not behave as an "efficient" one. Of course, such a conclusion is too general. So, in order to capture the shifting in the distribution shape it is necessary to employ a distribution index for instance one as:

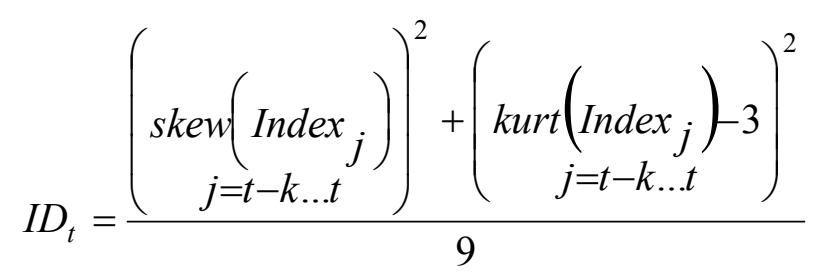

where skew, kurt are a measure of asymmetry of the distribution of the series around its mean (the Skewness of a symmetric distribution, such as the normal distribution, is zero, positive Skewness means that the distribution has a long right tail and negative Skewness implies that the distribution has a long left tail) and respectively a measure of the "peakedness" or "flatness" of the distribution of the series (the Kurtosis of the normal distribution is 3; if the kurtosis exceeds 3, the distribution is "peaked"-leptokurtic- relative to the normal and if the Kurtosis is less than 3, the distribution is "flat" -platykurtic-relative to the normal one).

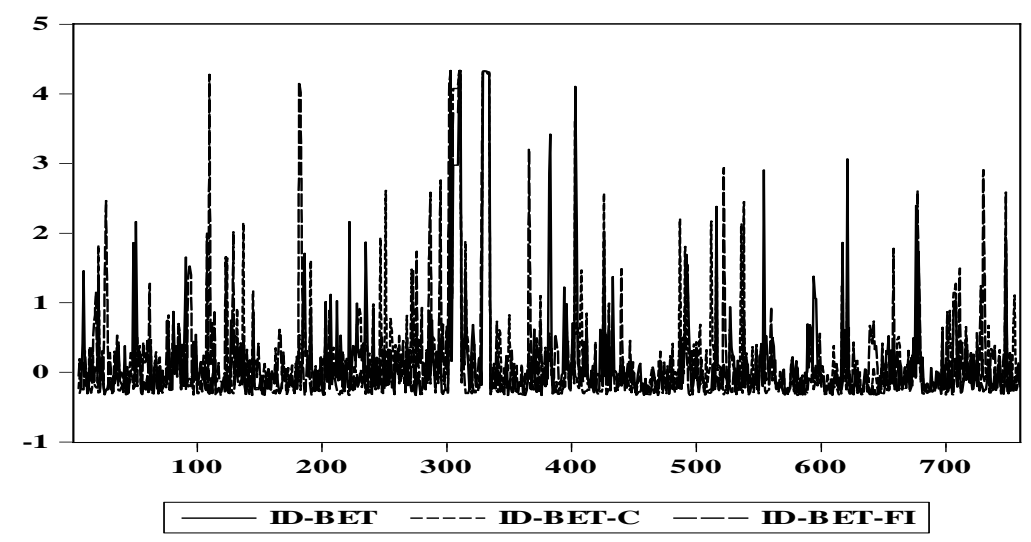

Fig. No. 3 - The distribution indexes

The distribution indexes display some important extreme points. Their existence could indicate the areas of "structural changes". Such areas could be better delimited by the dynamic of 
the market volatility.

For estimating the intrinsic volatility two proxies are involved (Graphic 4):

1. A volatility measure based on "High-Low" difference $\left(I_{H-L}\right)$ defined as:

$$
I_{t H-L}=\frac{\left(H_{t}-L_{t}\right)}{\left(\begin{array}{c}
\max \left(H_{i}\right)-\min \left(L_{i}\right) \\
i \in[t-k t] \quad i \in[t-k t]
\end{array}\right)} * 100
$$

with $k$ exogenous selected.

2. A volatility measure based on standard deviation $\left(I_{\sigma^{2}}\right)$ computed as:

$$
I_{t \sigma^{2}}=\frac{\sigma^{2} t X}{\sigma^{2} C_{i}} * 100
$$

where $\sigma^{2}{ }_{x}$ is the standard deviation of the $X_{t}=\left\lfloor O_{t} H_{t} L_{t} C_{t}\right\rfloor$ vector formed by the Open, High, Low, Close current prices and $\sigma^{2}{ }_{C}$ is the standard deviation of the Close prices over a $[t-k t]$ observation period.

Also for "structural points" areas detection is interesting to delimitate more accurate the subperiods with individual evolution of the indexes patterns.

As a first step, the behavior of the indexes is described inside as framework of an ARMA equation:

$$
y_{t}=\alpha_{1} y_{t-1}+\alpha_{2} M A_{4_{t}}
$$

where $M A_{6_{t}}=\frac{1}{6} \sum_{k=t-6}^{t} y_{k}$

For estimating the probability of "structural breaking points" the equation parameters stability over the observation sample is analyzed by involving a specific test.

The Quandt-Andrews Breakpoint Test tests for one or more unknown structural breakpoints in the sample for a specified equation. The idea behind the Quandt-Andrews test is that a single Chow Breakpoint Test is performed at every observation between two observations, $\tau_{1}$ and $\tau_{2}$. The $k$ test statistics from those Chow tests are then summarized into one test statistic for a test against the null hypothesis of no breakpoints between $\tau_{1}$ and $\tau_{2}$.

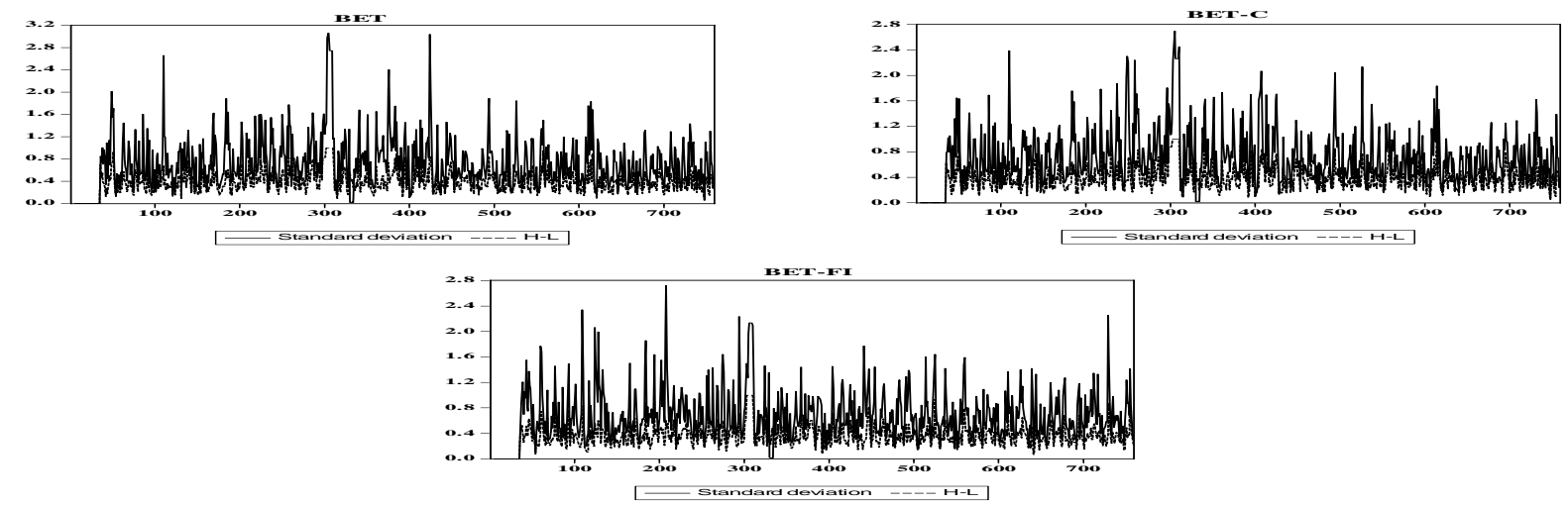

Graphic. no. 4-The market volatility

The individual test statistics can be summarized into three different statistics: the Sup or Maximum statistic, the Exp Statistic, and the Ave statistic (see [Andrews, 1993] and [Andrews and 
Ploberger, 1994]).

The results look like follows:

Table No.2

The Quandt-Andrews Breakpoint Test for indexes

\section{BET index}

Quandt-Andrews unknown breakpoint test

Null Hypothesis: No breakpoints within trimmed data

Equation Sample: 2759

Test Sample: 115644

Number of breaks compared: 530

\begin{tabular}{lcc}
\hline \hline Statistic & Value & Prob. \\
\hline \hline Maximum LR F-statistic (Obs. 329) & 410.5320 & 0.0000 \\
Exp LR F-statistic & 199.7509 & 1.0000 \\
Ave LR F-statistic & 2.738921 & 0.2173 \\
\hline \hline
\end{tabular}

Note: probabilities calculated using Hansen's (1997) method

\section{BET-C index}

Quandt-Andrews unknown breakpoint test

Null Hypothesis: No breakpoints within trimmed data

Equation Sample: 2759

Test Sample: 115644

Number of breaks compared: 530

\begin{tabular}{lcc}
\hline \hline Statistic & Value & Prob. \\
\hline \hline Maximum LR F-statistic (Obs. 329) & 412.6560 & 0.0000 \\
Exp LR F-statistic & 200.9003 & 1.0000 \\
Ave LR F-statistic & 2.742237 & 0.2167 \\
\hline \hline
\end{tabular}

Note: probabilities calculated using Hansen's (1997) method

\section{BET-FI index}

Quandt-Andrews unknown breakpoint test

Null Hypothesis: No breakpoints within trimmed data

Equation Sample: 2759

Test Sample: 115644

Number of breaks compared: 530

\begin{tabular}{lcc}
\hline \hline Statistic & Value & Prob. \\
\hline \hline Maximum LR F-statistic (Obs. 329) & 259.0599 & 0.0000 \\
Exp LR F-statistic & 124.3206 & 1.0000 \\
Ave LR F-statistic & 1.856996 & 0.4299 \\
\hline \hline
\end{tabular}

Note: probabilities calculated using Hansen's (1997) method 
Despite some differences between these tests, overall they suggest that the null of "no breakpoints" could be rejected for all the three indexes. Even more these tend to designate February 2007 as a major structural changes area.

Another interesting question that arise in the study of the three indexes as market' descriptors, is the question of the relationships between their reaction to endogenous / exogenous shocks. For instance, it could be noticed the fact that both measures of their volatility are co-integrated. This fact could be enlightened by employing a JOHANSEN co-integration test as follows:

JOHANSEN cointegration tests for volatility measures

Tabel No.3 (linear deterministic trend in data; intercept but no trend in co-integration equations and in test VAR)

I. For H-L measure

Unrestricted Co-integration Rank Test (Trace)

\begin{tabular}{ccccc}
\hline \hline $\begin{array}{c}\text { Hypothesized } \\
\text { No. of CE(s) }\end{array}$ & Eigenvalue & $\begin{array}{c}\text { Trace } \\
\text { Statistic }\end{array}$ & $\begin{array}{c}\text { 5 Percent } \\
\text { Critical Value }\end{array}$ & $\begin{array}{c}\text { 1 Percent } \\
\text { Critical Value }\end{array}$ \\
\hline \hline None ** & 0.197550 & 353.3817 & 29.68 & 35.65 \\
At most 1 ** & 0.153262 & 188.5373 & 15.41 & 20.04 \\
At most 2 ** & 0.081814 & 63.93085 & 3.76 & 6.65 \\
\hline \hline
\end{tabular}

Trace test indicates 3 co-integrating equation(s) at both $5 \%$ and $1 \%$ levels

$*(* *)$ denotes rejection of the hypothesis at the $5 \%(1 \%)$ level

\begin{tabular}{ccccc}
\hline \hline $\begin{array}{c}\text { Unrestricted Co-integration } \\
\text { Hypothesized } \\
\text { No. of CE(s) }\end{array}$ & Eigenvalue & $\begin{array}{c}\text { Maximum } \\
\text { Sigenvalue) } \\
\text { Statistic }\end{array}$ & $\begin{array}{c}\text { 5 Percent } \\
\text { Critical Value }\end{array}$ & $\begin{array}{c}\text { 1 Percent } \\
\text { Critical Value }\end{array}$ \\
\hline \hline None ${ }^{* *}$ & 0.197550 & 164.8444 & 20.97 & 25.52 \\
At most $1 * *$ & 0.153262 & 124.6064 & 14.07 & 18.63 \\
At most 2** & 0.081814 & 63.93085 & 3.76 & 6.65 \\
\hline \hline
\end{tabular}

Max-eigenvalue test indicates 3 co-integrating equation(s) at both 5\% and $1 \%$ levels

$*(* *)$ denotes rejection of the hypothesis at the $5 \%(1 \%)$ level

II. For standard deviation measure

Unrestricted Co-integration Rank Test (Trace)

\begin{tabular}{ccccc}
\hline \hline $\begin{array}{c}\text { Hypothesized } \\
\text { No. of CE(s) }\end{array}$ & Eigenvalue & $\begin{array}{c}\text { Trace } \\
\text { Statistic }\end{array}$ & $\begin{array}{c}\text { 0.05 } \\
\text { Critical Value }\end{array}$ & Prob.** \\
\hline \hline None * & 0.149916 & 283.1647 & 29.79707 & 0.0001 \\
At most 1* & 0.123160 & 161.5121 & 15.49471 & 0.0001 \\
At most 2* & 0.080758 & 63.07018 & 3.841466 & 0.0000 \\
\hline \hline
\end{tabular}

Trace test indicates 3 co-integrating eqn(s) at the 0.05 level

$*$ denotes rejection of the hypothesis at the 0.05 level

**MacKinnon-Haug-Michelis (1999) p-values

Unrestricted Co-integration Rank Test (Maximum Eigenvalue)

\begin{tabular}{|c|c|c|c|c|}
\hline $\begin{array}{l}\text { Hypothesized } \\
\text { No. of CE(s) }\end{array}$ & Eigenvalue & $\begin{array}{c}\text { Max-Eigen } \\
\text { Statistic }\end{array}$ & $\begin{array}{c}\text { 0.05 } \\
\text { Critical Value }\end{array}$ & Prob.** \\
\hline
\end{tabular}




$\begin{array}{ccccc}\text { None * } & 0.149916 & 121.6527 & 21.13162 & 0.0001 \\ \text { At most 1 * } & 0.123160 & 98.44190 & 14.26460 & 0.0000 \\ \text { At most 2 * } & 0.080758 & 63.07018 & 3.841466 & 0.0000\end{array}$

\footnotetext{
Max-eigenvalue test indicates 3 co-integrating eqn(s) at the 0.05 level

$*$ denotes rejection of the hypothesis at the 0.05 level

**MacKinnon-Haug-Michelis (1999) p-values
}

Both Maximum Eigenvalue and Trace tests indicate the existence of 3 co-integrating equations meaning that the reciprocal relations between indexes volatility could be clearly evidenced for the analysis period.

\section{Conclusions and further research}

The proposed analysis draw the image of the Romanian capital market as a typical emergent one, with some differences between the market indexes as it concerns the timing of the reactions to different kind of shocks, but with a strong base connection between them and enlighten the fact that the effects of the international financial crisis was started to appear from the last part of 2007. In order to develop a more consistent picture is minimally necessary to identify: a) the contagion mechanisms and b) the structural, functional and institutional effects exercised by the current global context.

\section{References:}

1. Andrews, D. W. K.,Tests for Parameter Instability and Structural Change With Unknown Change Point, Econometrica, 61(4), 821-856,1993

2. Andrews, D. W. K. and Ploberger W., Optimal Tests When a Nuisance Parameter is Present Only Under the Alternative, Econometrica, 62(6), 1383-1414,1994

3. Choudhry, Taufiq and Lin, Lu, Common Stochastic Trends Among Far East Stock Prices: Effects of the Asian Financial Crisis, EFMA 2004 Basel Meetings Paper.

4. Frankel,J.A,Schmukler,S.L - Crisis, Contagion and Country Funds: Effects on East Asia and Latin America, posted on: http://econ.worldbank.org/files/24699_Crises,_contagion,_country_funds_revised.pdf

5. Kregel,A -Yes, it did happen again - a Minsky crisis happened in Asia, Jerome Levy Economics Institute Working Papers, no.234,1998

6. Obstfeld,M.,Taylor,A.M -Global Capital Markets. Integration, Crisis and Growth (JapanUS Center UFJ Bank Monographs and International Financial Markets), Chambridge Press, 2004

7. Wan Mansor, M., and Marlinda, A, Interdependence Among the Asian Pacific Stock Market During the Asian Financial Crisis, ICFAI Journal of Applied Economics, Vol. 6, No. 5, 2007

8. Mueller, A., What's Behind the Financial Market Crisis? Ludwig von Mises Institute, Articles, http://mises.org/story/3111, 9/18/2008

9. Păun C.,Braşoveanu I.,Muşetescu R.,- Absolute risk aversion on the Romanian capital market, Romanian Journal of Economic Forecasting, 4/2007,p. 77-86

10. Skott,P -Financial innovation, deregulation and Minsky cycles, in Epstein, G, Gintis, H.M.:Macroeconomic Policy after the Conservative Era , Cambridge University Press, 1995

11. Schroeder,S.-A Minskian analysis of financial crisis in developing countries, University of Bremen, Bremen Contributions to institutional and Social Economics, no.50/2003 